\title{
Meeting Abstract
}

\section{Anthropometric proportionality models in sport population, and why it matters}

Modelos de proporcionalidad antropométrica en población deportista, y por qué es importante

\author{
Sánchez-Martínez $\mathrm{J}^{1}$,Almagià-Flores $\mathrm{A}^{1}$, Araneda-Araneda $\mathrm{A}^{2}$, Sánchez-García $\mathrm{P}^{2}$, Zúñiga-Reyes $\mathrm{M}^{2}$, \\ Plaza-Arancibia $\mathrm{P}^{3}$
}

\begin{abstract}
${ }^{1}$ Profesor. Laboratorio de Antropología Física y Anatomía Humana. Instituto de Biología. Facultad de Ciencias. Pontificia Universidad Católica de Valparaíso. Chile

${ }^{2}$ Kinesiologo. Escuela de Kinesiología. Facultad de Ciencias. Pontificia Universidad Católica de Valparaíso. Chile. ${ }^{3}$ Kinesiologa. Escuela de Kinesiología Universidad Andrés Bello, Facultad de Ciencias de la Rehabilitación, Viña del Mar, Chile.
\end{abstract}

In elite sports, for example the 100 meters race, it is possible to appreciate that athletes have a very similar morphostructure. This is not a coincidence, and it would be an argument to approach the morphology of an amateur subject to elite athletes in order to improve his sport performance.

The anthropometric proportionality or alometry is the relation between body parts. The use of a human reference has been proposed since the antiquity, as the Leonardo da Vinci's Vitruvian man. The proportionality can be used in sports to compare subjects with reference to a specific sport, looking to predict performance or modify the training program (diet or others) to resemble as much as possible to the elite athletes. Thus, anthropometric comparisons through a proportion model would have a great impact in sports.

The commonly used proportionality model is the Phantom (1), which uses an asexual and arbitrary human reference with specific anthropometric characteristics. Its usefulness is to adjust the anthropometric variables through proportionality obtaining Z-scores, which are the standard deviation respect to the Phantom model. Thus, the comparison between two subjects or samples through their Z-scores is possible. However, in sportsmen its applicability is limited due to the Phantom reference leads away of the morphological characteristics of athletes. In this way the results obtained are not representatives (2).

There are others proportionality models, not widely known, such as the Combinated (3) and the Scalable (4). They look to obtain more representative results by comparing the sample with a reference population with similar characteristics. Nevertheless, these two methods present some differences. First, the Combinated method gets the Z-scores though the comparison between the subjects and the combination between the reference population (e.g. .professional gymnasts) and Phantom. In contrast, the Scalable method makes a direct comparison between the subjects and 
Sánchez-Martínez J,Almagià-Flores A, Araneda-Araneda A, Sánchez-García P, Zúñiga-Reyes M, Plaza-Arancibia P. Anthropometric proportionality models in sport population, and why it matters. Mot. Hum. 2016;17 Supl 1:14-16

the reference population. Another difference is that the Combitaned method does not standardize the results, because it does not adjust the Z-scores by the height of the sample.

In this way, we have three proportionality methods to make comparisons between sportsmen: the Phantom method which gets two Z-scores for variable (of the subjects and the reference sport population); the Combinated method that obtains the Z-scores through an hybrid reference (combination between the reference population and Phantom); and the Scalable method, which gets the scores through a direct comparison between the subjects and the reference population. The question arises over which of these three methods we should use for proportionality comparisons between an amateur sample and elite sportsmen.

In 2008, Cabañas et al. (5) conducted a comparative study of the three model of proportionality described above in ten-years-old male school children. They concluded that the Z-values of the Combinated method presented some weakness because the values were not adjusted by the height. This did not generate real proportionality indexes, suggesting that the Scalable model may be more useful (5).

Another study performed by Almagia et al. (6) compared a male university soccer team to professional soccer players using the three models of proportion in order to find possible differences. In the Phantom model, they obtained similar Z-scores for body mass and breadths, differences in the range of [0.04 to 0.76] in girths, and differences in the range of [0.39 to 1.92] in skinfolds. This is how the Phantom model was used to find similarities between populations. When the Z-scores obtained in the Phantom, Combinated and Scalable model are compared, differences between them were seen. Statistically significant differences were found between the Phantom and Combinated model in skinfolds (triceps, biceps, iliac crest, supraespinal, abdominal, front thigh and medial calf). Between the Phantom and Scalable model they found significant differences in wrist girth and skinfolds (iliac crest, supraespinal, abdominal, frontal thigh and medial calf). Finally, statistically significant differences were found between the Combinated and Scalable model in hip and thigh girths.

It was found some inconsistent in the Combinated model when comparing the distribution of the Z-scores of the three methods, which could be due to values were not adjusted by the height (6). This inconsistent was also evidenced by the negative value obtained in the waist girth, which seems to be in contradiction with the high Z-scores obtained in iliac crest, abdominal and supraespinal skinfolds (6).

Lastly, the Phantom model presented non representative results, attenuating the differences between university and professional football players, as well as the Combinated model which obtained lower Z-scores with respect to the Scalable. This could underestimate some results and produce inaccuracies in the interpretation. 
In this way, there are some differences in the Z-scores when using different anthropometric proportion models, causing differences in the interpretation of the results. A mistake in interpretation could origin to wrong decisions in the training program of an athlete who intends to enhance his performance.

Thus, it is proposed the use of the Scalable method for the proportional comparisons between sportsmen of the same discipline. This method obtains more specific and consistent results through a direct comparison, which provides a better interpretation of the Z-scores in order to take decisions about the training program, nutrition or others variables for enhance the sport performance of athletes through the anthropometric proportional similarity.

\section{References}

1. Ross W, Wilson N. A stratagem for proportional growth assessment. Acta Paediatr Belg. 1974; 28: 169:182.

2. Cabañas MD, Maestre MI, Herrero A. Estudio de dos propuestas sobre el modelo phantom de proporcionalidad de Ross y Wilson. Biomecánica. 2009; 16(1): 7-12.

3. Lentini N, Verde P. El método combinado: una propuesta específica en proporcionalidad antropométrica. Archivos de Medicina del Deporte. 2004; 21(101): 223:229.

4. Cabañas MD, Maestre MI, Herrero A. Modelo estándar de proporcionalidad ontogénica: Propuesta de modificación del modelo estándar de referencia en cineantropometría al estudio de poblaciones en crecimiento. XXII congreso de la Sociedad Anatómica Española. España: 2005.

5. Cabañas MD, Maestre MI, Herrero A. Estudio de dos propuestas sobre el modelo phantom de proporcionalidad de Ross y Wilson. Biomecánica. 2008; 16(1).

6. Almagià A, Araneda A, Sánchez J, Sánchez P, Zúñiga M, Plaza P. Elección del modelo de proporcionalidad antropométrica en una población deportista; comparación de tres métodos. Nutrición Hospitalaria. 2015;32(03): 1228-1233.

\section{Correspondencia:}

Javier André Sánchez Martínez

Avenida Universidad 330, Curauma, Placilla.

+56999159105

j.sanchez@outlook.cl

Recibido: 01-03-2016 Aceptado: 15-03-2016

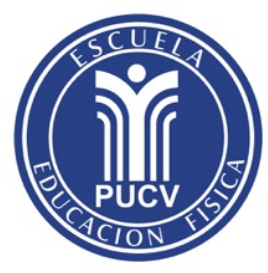

